\title{
THE HVEE ${ }^{14}$ C SYSTEM AT GRONINGEN
}

\author{
ANDREAS GOTTDANG, DIRKJ. W. MOUS
}

High Voltage Engineering Europa B.V., Postbus 99, 3800 AB Amersfoort, The Netherlands

and

\section{JOHANNES VAN DER PLICHT}

Centre for Isotope Research, University of Groningen, Nijenborgh 4, 9747 AG Groningen The Netherlands

\begin{abstract}
Since May 1994, a new-generation accelerator mass spectrometer (AMS) has been fully operational at the Centre for Isotope Research in Groningen, The Netherlands. The fully automated and high-throughput accelerator mass spectrometry (AMS) system, manufactured by High Voltage Engineering Europa (HVEE) is dedicated to radiocarbon analysis. The HVEE $4130{ }^{14} \mathrm{C}$ AMS is able to analyze up to 3000 samples per year. The system is characterized by simultaneous transport of all three isotopes $\left({ }^{12} \mathrm{C},{ }^{13} \mathrm{C},{ }^{14} \mathrm{C}\right)$ and ${ }^{14} \mathrm{C}$ analysis with a precision below $0.5 \mathrm{pMC}$ and a daily stability below $0.5 \mathrm{pMC}$. We present here a system description together with stability and performance measurements.
\end{abstract}

\section{INTRODUCTION}

Accelerator mass spectrometry (AMS) is an important dating tool in archaeology, geosciences, oceanography and other related research fields including biomedical applications. The ability to measure samples 1000 times smaller than those used in liquid scintillation or gas counting techniques together with high throughput broadens the applications of AMS for the future (Davis 1994; Mook 1984). When combined with precise radiocarbon dating, these advantages allow, for example, ${ }^{14} \mathrm{CO}_{2}$ tracing in seawater (Jones et al. 1990; von Reden et al. 1994).

At the Centre for Isotope Research in Groningen, low background measurements by decay counting $\left({ }^{14} \mathrm{C}\right.$ and $\left.{ }^{3} \mathrm{H}\right)$ and mass spectrometry $\left({ }^{2} \mathrm{H},{ }^{13} \mathrm{C},{ }^{15} \mathrm{~N},{ }^{18} \mathrm{O}\right)$ have been used for many years. A new generation high-precision and high-throughput ${ }^{14} \mathrm{C}$ AMS system has been in routine operation since May 1994. Because high-precision ${ }^{14} \mathrm{C}$ dating with low detection thresholds requires improved control over fractionation and contamination effects of the samples (Beukens 1993; Bonani et al. 1990; Suter 1990), the sample preparation technique with the graphitization process, the procedure for filling the AMS sample carriers and the carrier itself have also been improved. These improvements are discussed elsewhere (van der Plicht et al. 1995).

The HVEE $4130{ }^{14} \mathrm{C}$ AMS system (Mous, Gottdang and van der Plicht 1994; Purser et al. 1988, 1990; Purser 1992a), built by High Voltage Engineering Europa, is the second spectrometer of this type that measures all three carbon isotopes simultaneously. The high-throughput machine is capable of dating up to 3000 samples per year. Simultaneous transport of the three isotopes has clear advantages over serial injection (Wölfli 1987). With simultaneous injection, all individual isotopes are measured under the same conditions, which minimizes fractionation effects. Further, this "DC operation" provides an online diagnostic tool for the machine performance during measurements.

After a brief description of the system, we show some stability measurements performed on various sections of the ${ }^{14} \mathrm{C}$ AMS system. We present data that show the stability of the system together with performance measurements obtained from modern samples. Further results are presented in van der Plicht et al. (1995). 


\section{SYSTEM DESCRIPTION}

The principles of operation of the HVEE 4130 AMS system were described previously (Purser et al. 1988 , 1990; Purser 1992a,b,c). Figure 1 shows the layout of the machine. The system can be divided into five main sections: 1 ) the ion source; 2 ) the recombinator; 3 ) the Tandetron tandem accelerator; 4) the high-energy mass spectrometer; and 5) the computer control system with data acquisition.

1. A high current cesium sputter-type ion source with a hemispherical ionizer and an improved cesium vapor delivery system produces a $\sim 36 \mathrm{keV}$ negative ion beam from graphite samples. Up to 59 samples can be inserted and manipulated in this computer-controlled source, whereby the time for an unload and load cycle is $<40 \mathrm{sec}$. To minimize cross-contamination among samples, the targets are stored in a revolving wheel $100 \mathrm{~mm}$ from the sample under analysis. To avoid serious sample cratering by the sputtering $\mathrm{Cs}^{+}$beam, the loaded sample is moved during analysis perpendicular to the beam direction. Large cratering can introduce source fractionation and a varying beam emittance, which degrades overall system performance. The ion beam extracted from the source is focused with an einzel lens through a beam defining aperture.

2. The recombinator (Litherland and Kilius 1990,1991) consists of four second-order corrected $45^{\circ}$ magnets. The first pair of magnets analyzes the beam and separates the desired masses 12 , 13 and 14 at the symmetry plane of the recombinator by $c a .20 \mathrm{~mm}$. Moveable beam stops allow for every beam component to be injected and analyzed separately. A chopper wheel reduces the ${ }^{12} \mathrm{C}$ beam load for the accelerator and the high-energy spectrometer by a factor of $\mathrm{ca} .90$ (Purser 1992a). The second pair of magnets recombines the individual beams back on one track for simultaneous injection in the tandem. The recombinator is achromatic, i.e., the beam positions at the image of the recombinator are not influenced by small changes in beam energy ("Brown Achromat") (Purser 1992a).

3. In the Tandetron accelerator, the singly charged negative ions are focused (F'urser 1993) and accelerated to a terminal, which operates at $+2.5 \mathrm{MV}$. After charge exchange to the mean charge state $3+$, by collisions with argon atoms in a recirculating gas stripper canal, the ions are accelerated back to ground potential to reach an energy of $10 \mathrm{MeV}$. The $3+$ charge state is selected to overcome background problems from metastable molecules such as ${ }^{12} \mathrm{CH}_{2}{ }^{\mathrm{n}+}$ or ${ }^{13} \mathrm{CH}^{\mathrm{n}+}$. Mol-

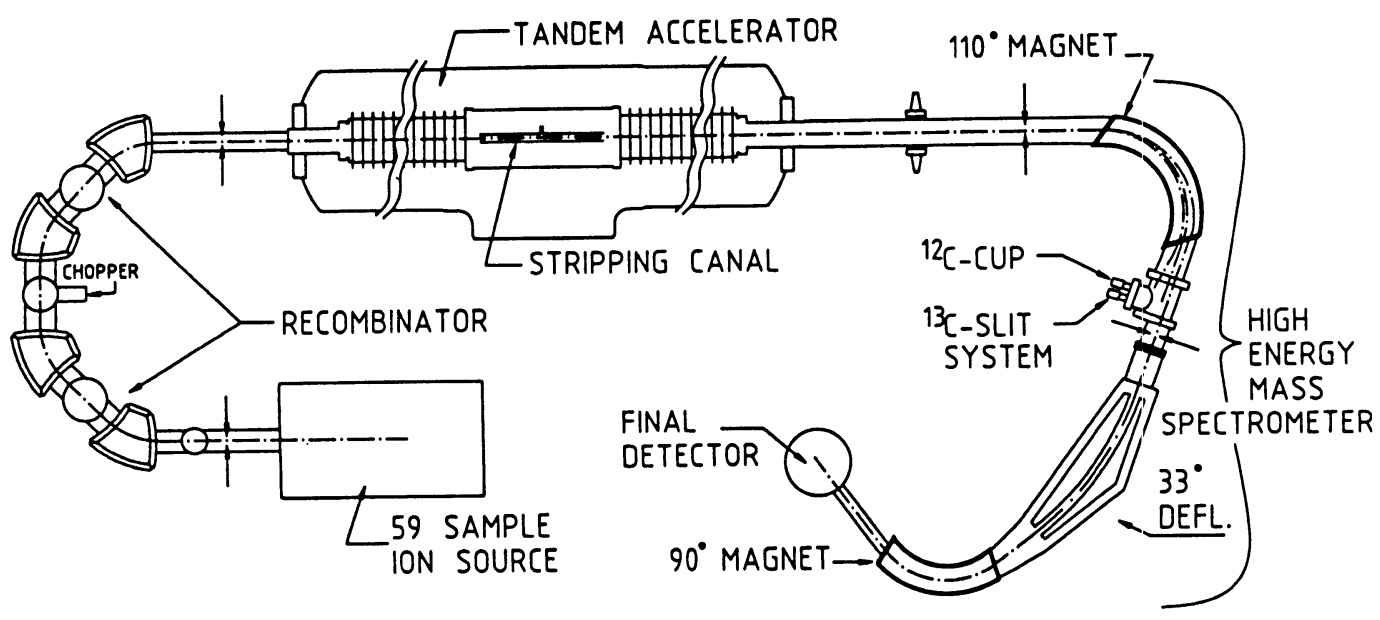

Fig. 1. Schematic layout of the HVEE ${ }^{14} \mathrm{C}$ AMS system 
ecule ions with a 3+ charge state have never been detected by AMS (Lee 1987). Specially designed inclined-field acceleration tubes (Purser 1992a) efficiently suppress ambiguities of ions with the same mass-energy product as the desired $10 \mathrm{MeV}^{14} \mathrm{C}^{3+}$ particles, which result from charge exchange processes during the acceleration to ground potential.

4. The final analysis is done with an achromatic high-energy spectrometer, consisting of a $110^{\circ}$ magnet, a $33^{\circ}$ electrostatic deflector and a $90^{\circ}$ magnet. The first magnet selects the $3+$ charge state and separates the three isotopes. The ${ }^{12} \mathrm{C}$ and ${ }^{13} \mathrm{C}$ beams are measured in individual Faraday cups, located in the image point of the double-focusing $110^{\circ}$ magnet. Typical currents obtained from samples produced with the previously mentioned preparation technique are in the range of 300 to $800 \mathrm{nA}$. The ${ }^{14} \mathrm{C}$ particles pass two additional dispersive elements, a $33^{\circ}$ electrostatic deflector, which blocks almost all residual ambiguities with the same mass energy product as $10 \mathrm{MeV}{ }^{14} \mathrm{C}^{3+}$, and a $90^{\circ}$ magnet for further background reduction, introduced by scattering effects at the $33^{\circ}$ deflector plates or by two-step charge-exchange processes with the residual gas. The latter background is also minimized by maintaining vacuum conditions in the ${ }^{14} \mathrm{C}$ spectrometer below $10^{-8}$ mbar. ${ }^{14} \mathrm{C}$ ions are detected in an isobutane-filled ionization chamber isolated from the vacuum system by a Mylar foil $\left(-250 \mu \mathrm{g} \mathrm{cm}^{-2}\right.$ thick$)$. This detector provides a dE/ $\mathrm{dx}$ and $\mathrm{a} \mathrm{E}_{\text {final }}$ signal. By gating these signals with standard electronic devices, all unwanted particles are eliminated from the spectrum. For a highly stable terminal voltage, the ${ }^{13} \mathrm{C}$ cup is provided with an integrated slit system. This setup creates a slit error signal, which is related to the beam displacement in the cup. Application of low bias operational amplifiers ( $\sim 1 \mathrm{pA})$ ensures that the measured ${ }^{13} \mathrm{C}$ current is not affected (Mous, Gottdang and van der Plicht 1994).

5. The complete low-level control of the system is done by fiber-optic links to a computer processing unit. The resolution and the stability of these controls are better than $10^{-3}$. Every highlevel action can be performed with two personal computers, one for the source control and one for overall system control and data acquisition. This system configuration allows for unattended automatic operation around the clock.

\section{STABILITY OF INDIVIDUAL MACHINE SECTIONS}

Stability is the major key factor for reliable high-precision measurements. Thus, we put special emphasis on different machine sections to ensure that the analysis is unaffected by drift or fractionation effects on a long-term basis.

\section{Recombinator}

The recombinator provides the simultaneous injection of the masses 12,13 and 14 into the accelerator and the high-energy spectrometer. To minimize fractionation effects resulting from possible misalignments of the individual beams with respect to the mechanical axis of the system, we optimized the recombinator components as described previously (Mous, Gottdang and van der Plicht 1994). Measurements showed that after this optimization, all three beams recombine within $0.3 \mathrm{~mm}$ and $0.4 \mathrm{mrad}$. The ion-beam radius at the image is $c a .3 \mathrm{~mm}$ and the half-angle divergence $12 \mathrm{mrad}$.

To confirm that no fractionation is created in the recombinator, we performed a scan with the recombinator magnets. Figure 2 shows the ${ }^{13} \mathrm{C} /{ }^{12} \mathrm{C}$ ratio, measured in the Faraday cups in the high-energy spectrometer. During the scan, the beams are shifted by $c a .8 \mathrm{~mm}$ in symmetry plane of the recombinator. The measured relative stability of the magnet current is $\sim 3.5 \times 10^{-4}$ in $12 \mathrm{~h}$. The range in which the system works during normal operation is indicated in the graph and corresponds to a variation of $<0.2 \mathrm{~mm}$. This measurement shows that fractionation effects in the recombinator are negligible. 


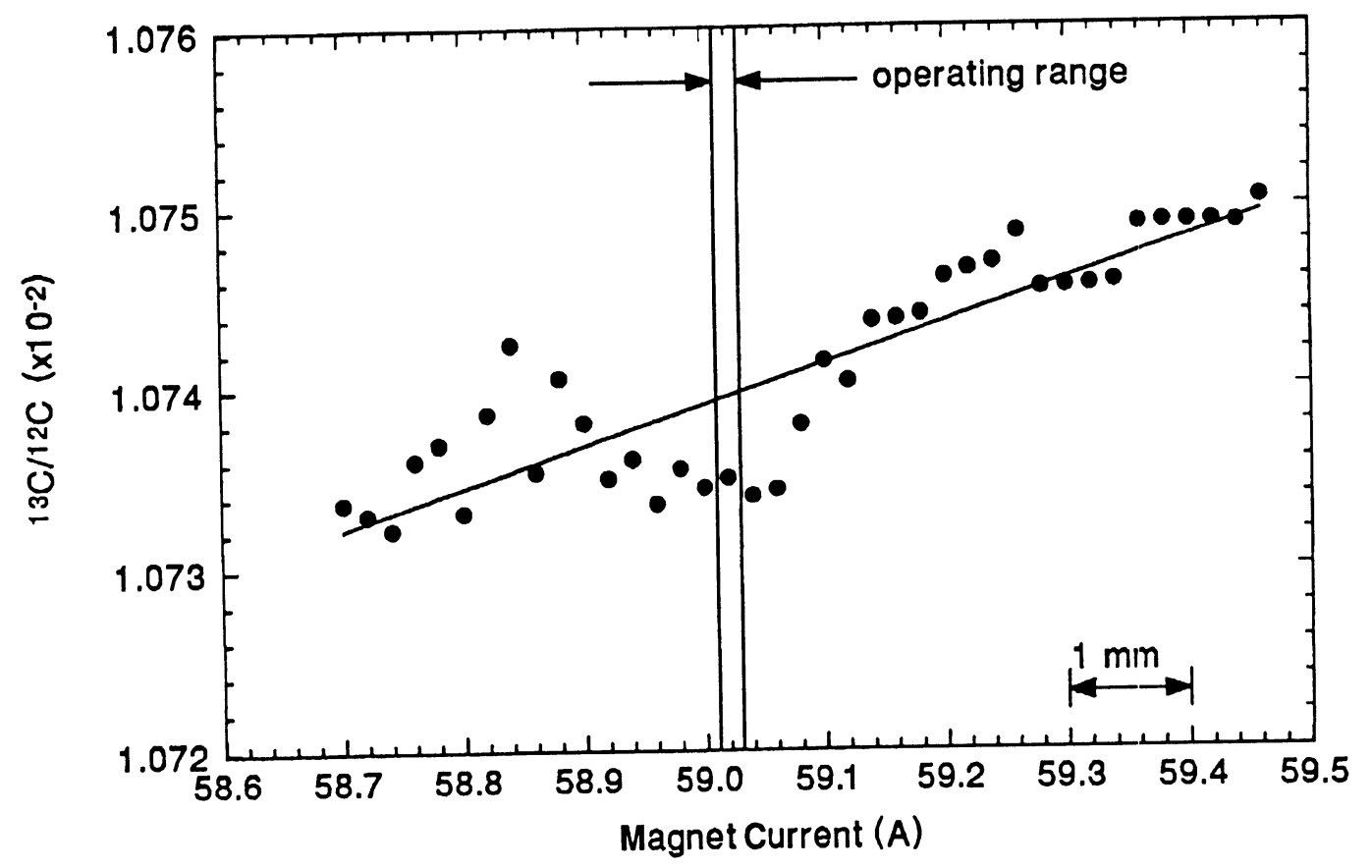

Fig. $2 .{ }^{13} \mathrm{C} /{ }^{12} \mathrm{C}$ ratio during a scan with the recombinator magnets

\section{Slit Feedback Stabilization}

Figure 3 shows the measured current from the ${ }^{13} \mathrm{C}$ cup and the corresponding slit error signal during a scan with the $110^{\circ}$ magnet. During this measurement, the error signal was not taken as the reference for the terminal voltage. The linear slope of the slit error signal at $\pm 1 \mathrm{~mm}$ around the zero position makes it possible to relate the error signal to the actual beam displacement in the image point after the $110^{\circ}$ magnet. This information can be easily used to tune the high-energy spectrometer from day to day in exactly the same manner. The time dependence of the error signal and the related beam displacement are shown in Figure 4. The ion beam was intentionally shifted with the $110^{\circ}$ magnet by $0.3 \mathrm{~mm}$ and the slit feedback was switched off. After $1.3 \mathrm{sec}$, the slit feedback was activated and the beam was forced back to the zero position. The graph shows that the small fluctuations of $c a .0 .15 \mathrm{~mm}$ disappear when the slit feedback stabilization is switched on. We also note that by using slit feedback stabilization, the center of the beam in the high-energy mass spectrometer is inherently stable below $0.1 \mathrm{~mm}$ over the long term.

\section{MACHINE PERFORMANCE}

Figure 5 shows a typical ${ }^{14} \mathrm{C}$ spectrum from a sucrose sample $(150.61 \mathrm{pMC})$. Only the $\mathrm{E}_{\text {final }}$ detector of the ionization chamber is used here; no gating with the $\mathrm{dE} / \mathrm{dx}$ detector signal was done. It took 22 min to measure the 201,258 counts in the ${ }^{14} \mathrm{C}$ peak (counting statistics: $2.2 \%$ ). The insert shows that the ${ }^{14} \mathrm{C}$ peak is clearly separated from the neighboring peaks and the ${ }^{14} \mathrm{C}$ count rate can be easily extracted by using a software window. The exact origin of the other two peaks is still under investigation. We believe multiple charge exchanges and scattering effects are involved here. 


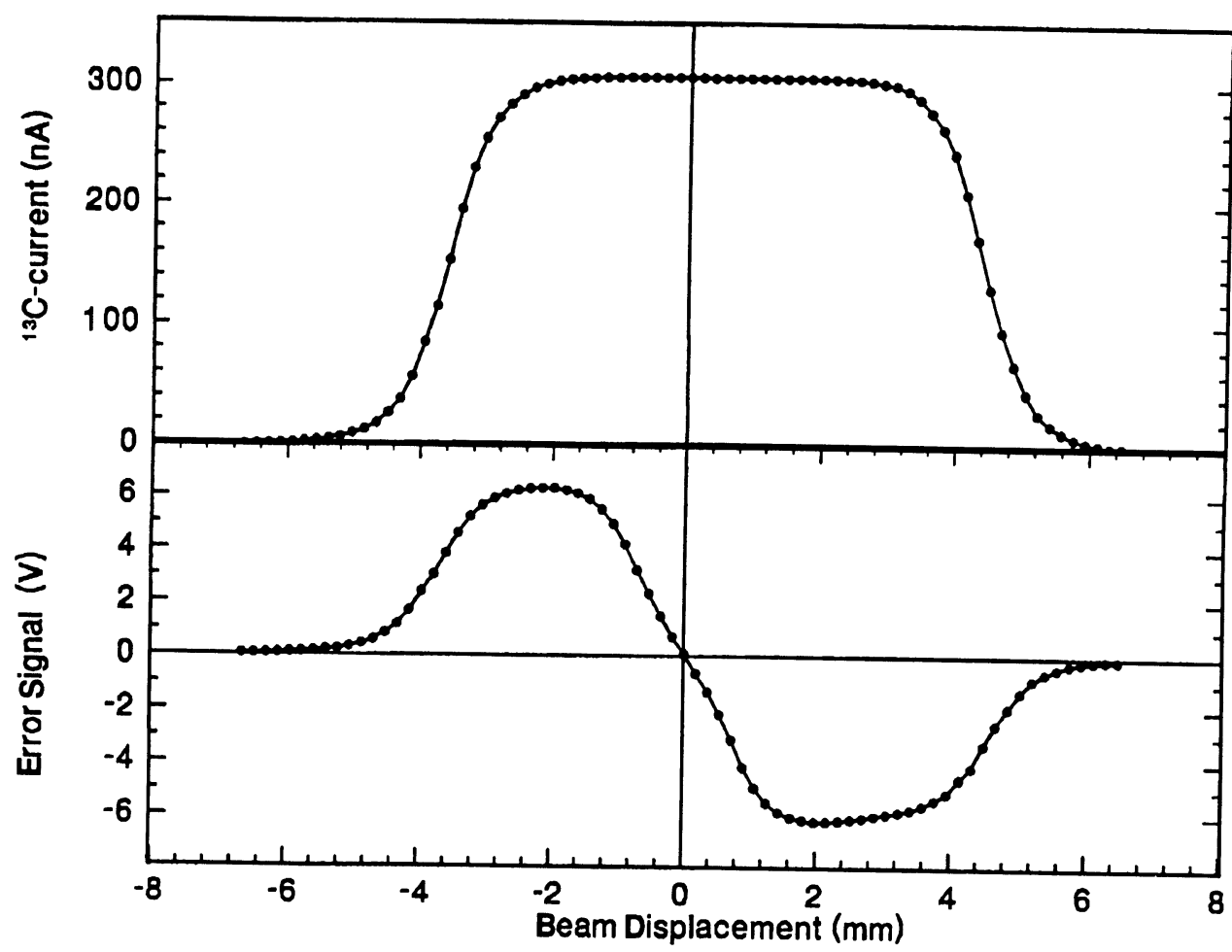

Fig. $3 .{ }^{13} \mathrm{C}$ current with corresponding slit error signal during a scan with the 110 magnet over the ${ }^{13} \mathrm{C}$ cup

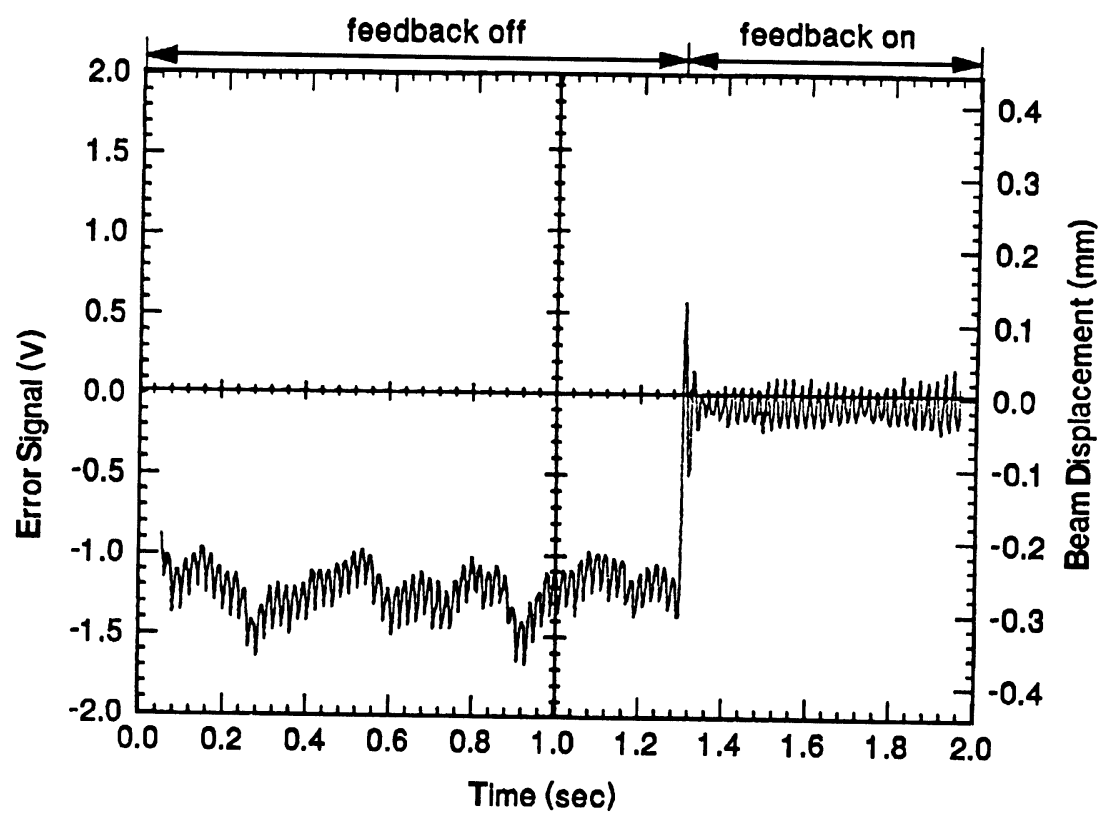

Fig. 4. Measured slit error signal and corresponding beam displacement with slit feedback stabilization switched off and on 


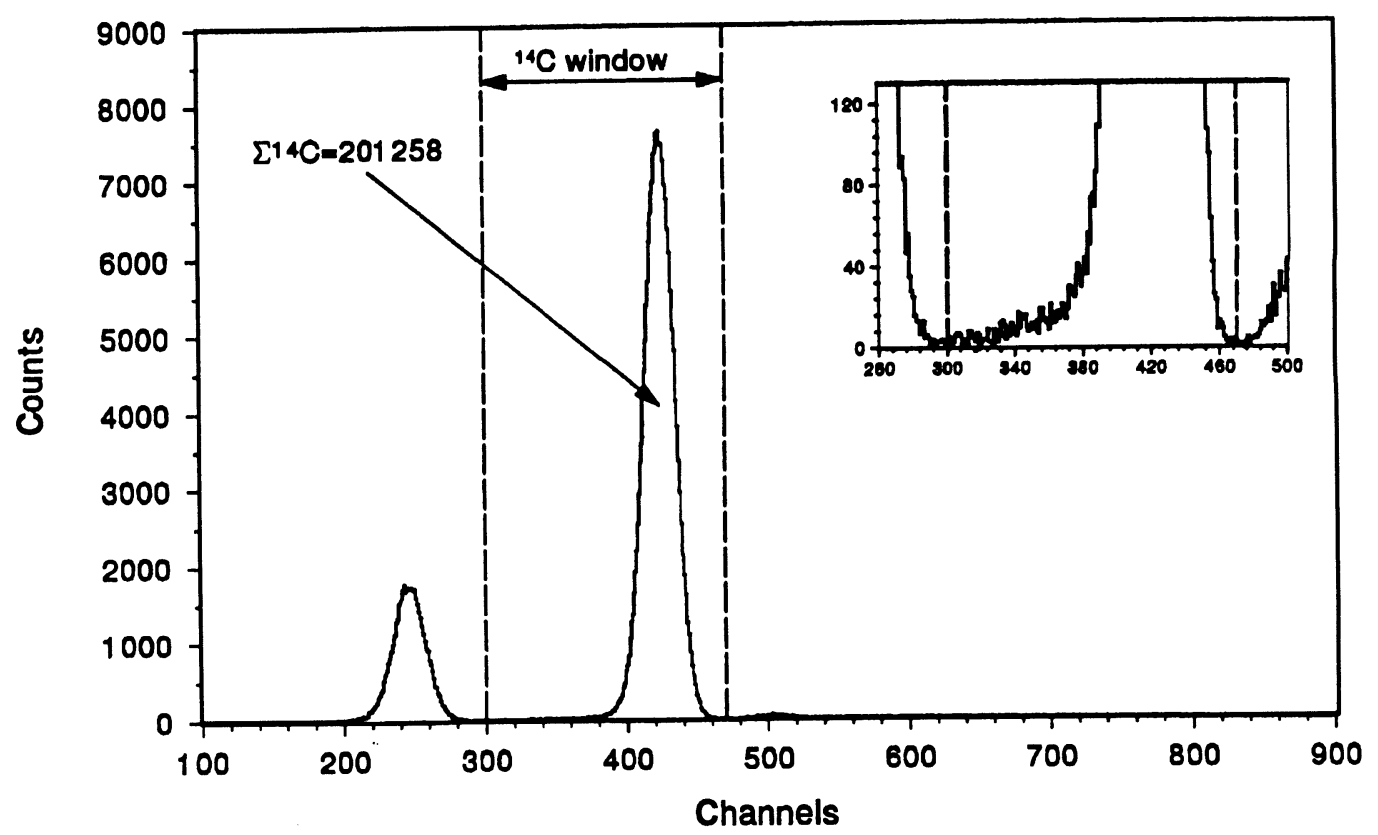

Fig. 5. Ungated ${ }^{14} \mathrm{C}$ energy spectrum measured in $\sim 22 \mathrm{~min}$ from a sucrose (150.61 $\mathrm{pMC}$ ) sample

In Figure 6, the ${ }^{13} \mathrm{C} /{ }^{12} \mathrm{C}$ ratio is measured for $>2 \mathrm{~h}$. We use six sucrose samples in 12 runs; every sample is loaded twice. Each data point in the graph represents the mean of 79 current measurements carried out in $40 \mathrm{sec}$. No long-term drift is observed on a per mil level. Note that all data points are within $4 \%$. The small drift for each individual run is probably related to the warming of the sample by the cesium sputter beam. To avoid these drifts, an improved target cooling clamp has been installed and is being studied.

Table 1 shows the mean and the standard deviation of all three isotope ratios, determined sequentially for two days. The 11 sucrose samples were produced in one batch using the preparation tech-

TABLE 1. Results from measurements of two succeeding days. The ${ }^{12} \mathrm{C}$ and ${ }^{13} \mathrm{C}$ currents were in the range of 500 to $650 \mathrm{nA}$ on both days.

\begin{tabular}{cccccccc}
\hline Sucrose & \multicolumn{2}{c}{${ }^{13} \mathrm{C} /{ }^{12} \mathrm{C}$} & \multicolumn{2}{c}{${ }^{14} \mathrm{C} /{ }^{13} \mathrm{C}$} & \multicolumn{3}{c}{${ }^{14} \mathrm{C} /{ }^{12} \mathrm{C}$} \\
\cline { 2 - 7 } $150.61 \mathrm{pMC}$ & $\begin{array}{c}\text { Mean } \\
\left(\times 10^{-2}\right)\end{array}$ & $\sigma_{\text {rel }}$ & $\begin{array}{c}\text { Mean } \\
\left(\times 10^{-10}\right)\end{array}$ & $\sigma_{\text {rel }}$ & $\begin{array}{c}\text { Mean } \\
\left(\times 10^{-12}\right)\end{array}$ & $\sigma_{\text {rel }}$ & $\begin{array}{c}\sigma \\
(\mathrm{pMC})\end{array}$ \\
\hline $\begin{array}{c}\text { 1st day } \\
\text { 6 samples }\end{array}$ & 1.0719 & $0.5 \% 0$ & 1.4705 & $1.7 \% 0$ & 1.5762 & $1.5 \% 0$ & 0.23 \\
$\begin{array}{c}2.2 \% \text { statistics } \\
\text { 2nd day } \\
\text { 5 samples }\end{array}$ & 1.0696 & $1.8 \% 0$ & 1.4718 & $1.8 \% 0$ & 1.5743 & $3.1 \% 0$ & 0.48 \\
$\begin{array}{c}1.7 \% \text { statistics } \\
\text { Difference between } \\
\text { means of both } \\
\text { days }\end{array}$ & $2.1 \% 0$ & $0.9 \% 0$ & $1.2 \% 0(0.18 \mathrm{pMC})$ \\
\hline
\end{tabular}




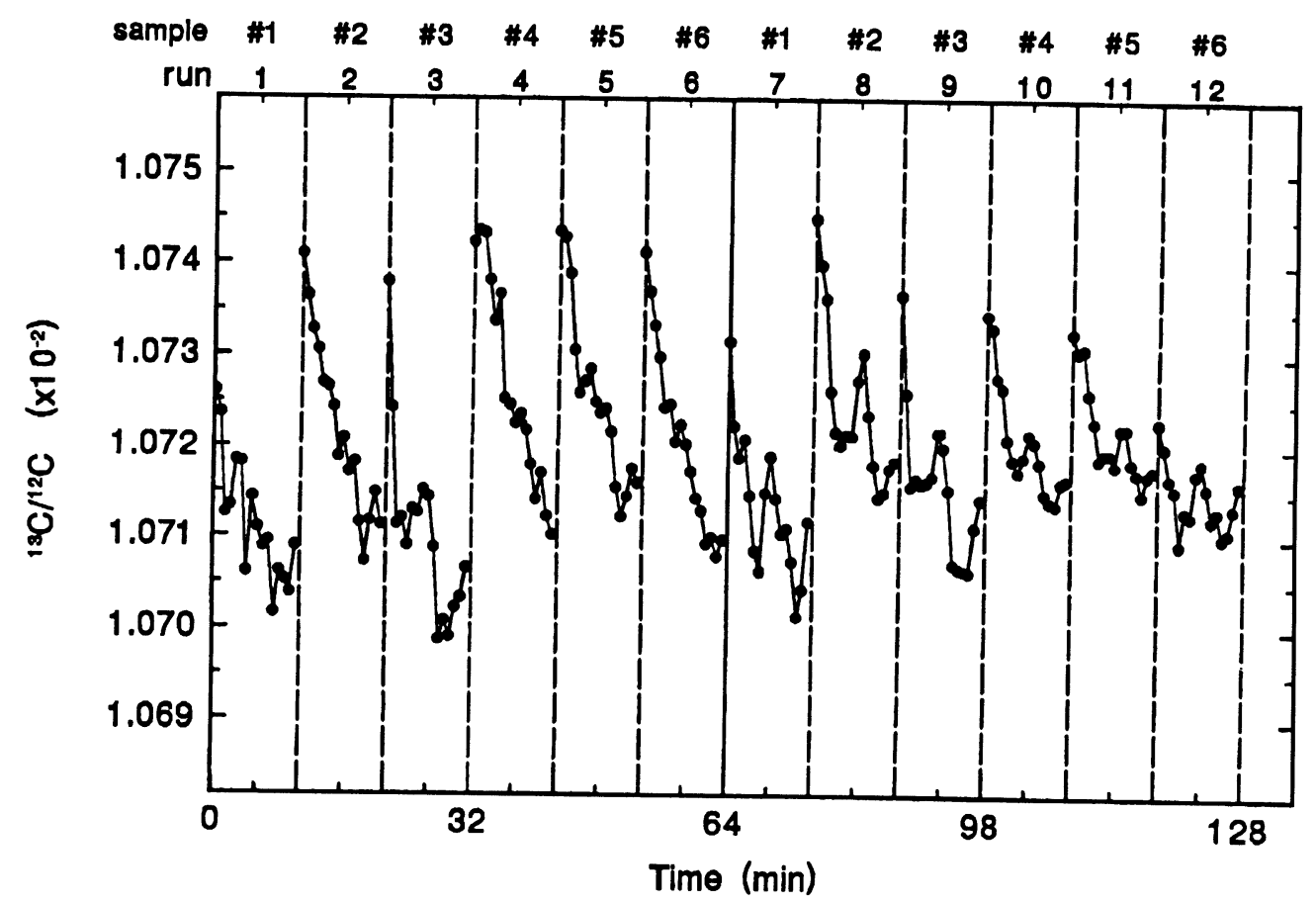

Fig. 6. Stability measurement of the ${ }^{13} \mathrm{C} /{ }^{12} \mathrm{C}$-ratio over $2 \mathrm{~h}$ for six different sucrose samples. Each sample was loaded twice in the ion source.

nique developed by van der Plicht et al. (1995). The counting statistics on the two days were $2.2 \%$ and $1.7 \%$, respectively. The ion source and the terminal voltage were switched off between days. We rejected no data block and used only a simple software window for the ${ }^{14} \mathrm{C}$ counts from the $\mathrm{E}_{\text {final }}$ detector. Table 1 shows that a precision $<0.5 \mathrm{pMC}$ is obtainable on a routine basis. We achieved a daily stability below $0.5 \mathrm{pMC}$ with this AMS system.

\section{ConCLusion}

The fully automated and high-throughput $\mathrm{HVEE}{ }^{14} \mathrm{C}$ AMS system at the University of Groningen is fully operational. Special emphasis has been placed on critical components of the AMS machine to reduce machine fractionation and to increase long-term stability. The recombinator provides simultaneous injection with negligible fractionation. The simultaneous analysis of all three carbon isotopes is an online diagnostic tool, which checks the performance of the AMS continuously. The slit feedback stabilization guarantees a stable beam transport in the high-energy spectrometer on a longterm basis. Precision measurements with modern samples have shown that a precision below 0.5 pMC is obtainable on a routine basis with a daily stability below $0.5 \mathrm{pMC}$.

\section{ACKNOWLEDGMENTS}

The Groningen ${ }^{14} \mathrm{C}$ AMS was funded by the University of Groningen and the Ministry of Economic Affairs, The Hague, The Netherlands. We thank K. H. Purser and A. E. Litherland and his group for many fruitful discussions. 


\section{REFERENCES}

Beukens, R. P. 1993 Radiocarbon accelerator mass spectroscopy: Background and contamination. Nuclear Instruments and Methods in Physics Research B79: 620-623.

Bonani, G., Eberhardt, P., Hoffmann, H. J., Niklaus, Th. R., Suter, M., Synal, H. A. and Wolfli, W. 1990 Efficiency improvements with a new stripper design. $\mathrm{Nu}$ clear Instruments and Methods in Physics Research B52: 338-344.

Davis, J. C. 1994 AMS beyond 2000. Nuclear Instruments and Methods in Physics Research B92: 1-6.

Jones, G. A., McNicol, A. P., von Reden, K. F. and Schneider, R. J. 1990 The National Ocean Sciences AMS Facility at Woods Hole Oceanographic Institution. Nuclear Instruments and Methods in Physics Research B52: 278-284.

Lee, H. (ms.) 1987 Study of carbon-14 detection and dating using accelerator mass spectrometry. $\mathrm{Ph}$. $\mathrm{D}$. dissertation, University of Toronto: $152 \mathrm{p}$.

Litherland, A. E. and Kilius, L. R. 1990 A recombinator for radiocarbon accelerator mass spectrometry. $\mathrm{Nu}$ clear Instruments and Methods in Physics Research B52: 375-377.

1991 Mass recombinator for accelerator mass spectrometry. US Patent No. 5.013.923.

Mook, W. G. 1984 Archaeological and geological interest in applying ${ }^{14} \mathrm{C}$ AMS to small samples. Nuclear Instruments and Methods in Physics Research B5: 297302.

Mous, D. J. W., Gottdang, A. and van der Plicht, J. 1994 Status of the first HVEE ${ }^{14} \mathrm{C}$ AMS in Groningen. $\mathrm{Nu}$ clear Instruments and Methods in Physics Research B92: 12-15.

Purser, K. H. 1992a A high throughput ${ }^{14} \mathrm{C}$ accelerator mass spectrometer. In Long, A. and Kra, R. S., eds., Proceedings of the 14 th International ${ }^{14} \mathrm{C}$ Conference. Radiocarbon 34(3): 458-467.

1992b Acceleration apparatus which reduced background of accelerator mass spectrometry measurements of ${ }^{14} \mathrm{C}$ and other radio nuclides. U.S. Patent No. 5.120.956.

1992c Accuracy of AMS isotopic ratio measurements. U.S. Patent No. 5.118.936.

1993 Injection system for tandem accelerators. U.S. Patent No. 5.247.263.

Purser, K. H., Smick, T., Litherland, A. E., Beukens, R. P., Kieser, W. E. and Kilius, L. R. 1988 A third generation ${ }^{14} \mathrm{C}$ accelerator mass spectrometer. Nuclear Instruments and Methods in Physics Research B35: 284-291.

Purser, K. H., Smick, T. H. and Purser, R. K. 1990 A precision ${ }^{14} \mathrm{C}$ accelerator mass spectrometer. Nuclear Instruments and Methods in Physics Research B52: 263-268.

Suter, M. 1990 Accelerator mass spectroscopy: State of the art in 1990. Nuclear Instruments and Methods in Physics Research B52: 211-223.

van der Plicht, J., Aerts, A. T., Wijma, S. and Zondervan, A. 1995 First results from the Groningen AMS Facility. Radiocarbon, this issue.

von Reden, K. F., Schneider, R. J., Cohen, G. J. and Jones, G. A. 1994 Performance characteristics of the 3 MV Tandetron AMS system at the National Ocean Sciences AMS facility. Nuclear Instruments and Methods in Physics Research B92: 7-11.

Wölfli, W. 1987 Advances in accelerator mass spectrometry. Nuclear Instruments and Methods in Physics Research B29: 1-13. 